\title{
DETERIORATION OF FIRE-KILLED PULPWOOD STANDS IN EASTERN CANADA ${ }^{1}$
}

\author{
BY A. J. SKolko
}

\author{
Forest Pathologist, Dominion Laboratory of Forest Pathology, \\ University of New Brunswick, Fredericton, N.B.
}

\section{INTRODUCTION}

The extensive forest fires of 1923, 1932, and 1941' in Eastern Canada suggest that conditions of extremely high fire hazard coincide with a nineyear cycle. During May, 1941, in the Lake St. John and North Shore regions of Quebec, the rainfall generally amounted to less than one inch and as low as 0.17 inches at certain points of observation. This compares with a general average of between two and three inches for the same month in the succeeding two years. Under such conditions of extreme drought fires are almost impossible to control because of the rapidity with which they spread, often involving thousands of square miles of valuable pulpwood stands.

For the Province of Quebec ${ }^{2}$ alone it has been estimated that in 1923 about 4,749 square miles, or over 3 million acres containing 4,140,356 cords of merchantable wood were burned. In 1932 the area burned was estimated at 1,605 square miles or $1,027,159$ acres containing $1,168,159$ cords of merchantable wood, and in 1941 about 2,485 square miles or $1,590,234$ acres on which $3,328,126$ cords were estimated. One can readily appreciate the magnitude of the operations which must be undertaken in order to salvage these large areas of fire-killed pulpwood stands. Final control of such widespread fires is dependent upon rainfall sufficient to reduce the inflammability of the forest.

The lack of public conscience, particularly among colonists and blueberry pickers, in failing to take adequate precautions during periods of high hazard constitutes one of the greatest problems facing fire prevention agencies. This together with inadequate fire fighting equipment and means of rapid transportation, can not but help lead to the expectation that, under unfavourable conditions of rainfall, the problem of salvaging fire-killed stands following such disastrous fires will be a recurring one. In spite of increased efficiency of fire protective organizations, it is highly problematical whether it will be possible to control fres under such extreme conditions of fire hazard until intensive forestry becomes a reality in Canada. In the wake of the forest fire there is left a blackened, denuded countryside with the tombstones of a once green forest to mark the grave. A forest of charred trunks bearing only the burned stubs of formerly heavily laden branches stands in the smouldering soil.

1 Contribution No. 898 from the Division of Botany and Plant Pathology, Science Service, Department of Agriculture Ottawa.

${ }^{2}$ Figures supplied by the Forestry Service, Department of Lands and Forests, Province of Quebec. 


\section{The Problem of Salvage}

Contrary to popular conception, even the most severe fire does little actual damage to the merchantable wood through burning. Directly after the fire, except for some charring of dead branches, knots and wounded areas of the trunk, the wood of the main stem remains quite intact. Even when the entire crown including the foliage, smaller branches and twigs is consumed by the fire and the bark is deeply charred, the protection of the bark and the moisture content of the wood itself prevent the wood in most cases from charring. Rarely is the bark of living trees penetrated and the underlying wood charred. No estimate of the amount of merchantable wood destroyed directly by fires has been made under eastern conditions. In the West, although conditions may be very different, it has been calculated that "the initial losses through destruction of merchantable wood are negligible, amounting to only 3 or 4 per cent of the stand volume" (Beall, et al, 1935). It is likely that immediate losses in the East, even under severe conditions of burn, are no higher. After the tender cambial layer under the bark is destroyed by the fire and the tree thus killed, real destruction begins, for the dead tree has become highly susceptible to decay caused by wood-destroy. ing fungi, subject to windfall, and then extremely rapid deterioration. The rate at which this decay progresses largely determines the period of economical salvage. The far-reaching effect of fire on the soil and subsequent forest crops goes beyond the scope of the salvage problem. However, the more or less complete destruction of the humus, leaving only the loosened mineral soil, together with the increased exposure to wind as a result of the remov. al of the protection provided by the foliage, has an important bearing on the amount of windfall and subsequent decay.

If the burned-over area could be immediately salvaged, the direct loss would be negligible. This, of course, may not be physically possible because of the large area involved, in which case the salvage operation must extend over a number of years. The burned-over area may be physically inaccessible within the salvage period and thus become a total loss. It may, however, be possible to adjust working plans to make these areas accessible within a shorter time than in the normal course of operation. The areas to be salvaged may be economically inaccessible. For example, working plans and improvements involving large expenditures likely have been already made for other areas. The loss involved in abandoning completed improvements may be prohibitive or may offset any advantage gained by early salvage.

Other factors which must be considered in planning salvage are numerous, some of which would appear even to favour operation in burned stands over that in green stands. One might expect cutting costs to be lower in fire-killed stands. There is less swamping and limbing and less brush to be cleared in road building. The wood, being dry, is much lighter and easier to handle. On the other hand, felled trees tend to lie closer to the ground since most of the branches have been burned off or break in felling and this makes bucking more difficult. There also tends to be more 
breakage during felling of the fire-killed trees, although in trees of small diameter such as are usually encountered in pulpwood operations this factor is not serious.

On actual operations it has been found that cutting costs are in fact higher on burned-over areas. It would appear that, offsetting any of the advantages, is the fact that labour costs are higher by reason of the high turn-over. The depressing effect on the men of constant association with the black dust of charred wood and bleak surroundings is largely responsible for a continuous migration from these camps. In addition, perhaps because of the depressed attitude and resulting carelessness of the cutters, much valuable wood is left and utilization control made difficult.

Driving of the drier fire-killed pulpwood is less difficult because the wood floats easily, giving higher capacity to streams. Losses in sinkage are lower. Perhaps of greater significance is the fact that costs of rail and truck transportation of the dry, barked wood are lower than that of green wood because the wood is much lighter and because there is a greater solid content of wood per cord.

All these factors must be considered in the light of mill requirements and the incentive offered by government stumpage reductions. From the mill standpoint fire-killed wood is less desirable, except for the fact that the bark has been removed, because of its hardiness, the tendency to include grit, particularly if the trees have been attacked by insects or have checked in drying, and because of the presence of burned wood which must be scrupulously excluded since the charred particles can not be bleached from the paper. As sometimes happens a burned branch stub may extend into the centre of the bole and thus leave a pocket of charred wood which es. capes detection during cleaning. This may result in spoilage of a large quantity of pulp. Finally, the weathered exposed surface of trees left standing after the bark has fallen away will darken the pulp and this is undesirable for quality papers.

In any case it is entirely likely that salvage will be carried on for a number of years and it is of the utmost importance to be able to predict what the rate of deterioration will be from year to year and for how many years the wood will remain sufficiently sound to justify salvage. This information is basic to planning the time of commencement of salvage, the areas to be cut first, the number of years during which salvage may be profitably carried on, and consequently the capacity of improvements to be made. Lack. ing precise or even approximate data on the rate of deterioration, the planning of salvage operations becomes a gamble with the only guidance being the experience of the individual or company on former salvage operations, supplemented by casual observations. 


\section{REVIEW OF Literature}

When the problem of salvaging the burned-over areas following the 1941 fires presented itself, it became evident how little information on rate of deterioration applicable to eastern Canadian conditions was available. A number of investigations have been reported for the eastern United States but these deal with deterioration following ground fires or with hardwood species. It is well known that deterioration of trees killed by ground fire proceeds much more rapidly than in those killed by severe fires in which the crown and bark of the whole tree are burned. This became apparent from a preliminary study in which an attempt was made to obtain information on the rate of deterioration by an analysis of stands killed by fire several years previously, a method which was satisfactorily employed by Kimmey and Furniss (1943) in the Pacific Northwest for Douglas fir. It was found in this preliminary study that this method could not be used because most of the areas available were burned over by ground fires and that deterioration had progressed so rapidly that salvage was not possible even after as short a time as two years. The relatively rapid deterioration of trees that die as a result of insect attack either through repeated defoliation or by the action of bark beetles as reported by Riley (1940) and by Riley and Skolko (1942), is not unlike that in trees killed by ground fire or only lightly charred in the lower part of the trunk. The problem which confronted operators in Eastern Canada was essentially one of deterioration in coniferous stands following severe crown fire.

The studies on deterioration in the Pacific Northwest by Knapp (1912), Beall, Kimmey, and Rapraeger (1935), Furniss (1937), Kimmey and Furniss (1943), and others, provide little information applicable to eastern conditions since these investigations ceal mainly with Douglas fir of large diameters salvaged for saw logs. Richmond and Lejeune (1945) have published a comprehensive report on deterioration of fire-killed white spruce by wood. boring insects in northern Saskatchewan. This investigation, however, deals largely with insect infestation as it affects sawn lumber and covers only the first two years after fire when insect activity practically ceases. Depreciation in such cases results from the insect tunnels and wood checking, factors which are only of secondary importance in a consideration of pulpwood deterioration.

Pepler (1931) has prepared a number of charts on rate of deterioration among which are two on deterioration of fire-killed spruce. The basis for these data is not stated other than that the charts were prepared from miscellaneous information based on past and present experiences and "represent average percentages for 6.12 cases". It is stated that only a small amount of data was available and that "the percentages arrived at are general averages". The necessity of a systematic study was stressed. The chart for spruce after severe fire shows losses of $1,4,6.5,10$, and 14 per cent after 1, 2, 3, 4 , and 5 years respectively while for spruce after light fire the losses were estimated at 14, 26, 50,76, and 90 per cent for the first five years. As far as the writer is aware no other papers dealing with deterioration of fire-killed pulpwood stands have been published. 
Certain general principles on deterioration of fire-killed stands based on experience may be postulated, but such information is usually only vaguely relative and often contradictory. To provide more reliable data on the rate of deterioration under given conditions the present study was undertaken. At best, these data can only be used as an index in estimating the rate of deterioration for any given burn. Conditions on any large area vary greatly and the reduction of these conditions to a measurable basis is hardly possible. Besides, it is not feasible in such a study to cover all the conditions which may be encountered. Within these limitations it is hoped that the present study may provide a better basis for the estimation of rate of deterioration than has been heretofore possible.

The calculation of loss through deterioration for any given stand is in theory a relatively simple one, involving only the determination of the amount of merchantable wood present at the time of the fire'and the amount of wood that can be utilized at the end of any given period of time following the fire, the difference being the amount lost through deterioration. In practice, the determination of the amount of wood present at the time of the fire can not be considered as accurate, since it must be based upon estimate. It is difficult to analyze the proportion of the loss attributed to the various agencies such as fungi, insects, windthrow and breakage, and to determine to what extent they are interdependent. The effect of the various environmental factors, of the conditions resulting from the fire, and of the com. position of the stand itself complicates the problem immeasurably. These considerations, even if only in a general way, must be understood in order to predict the rate of deterioration under any combination of conditions which may be encountered.

\section{Classification of Severity of Burn}

Experience has shown that the most obvious factors affecting deterioration are tree species and severity of burn. With this in mind the six sample plots described below were established during the summer of 1942 in areas burned over by the fires of May, 1941. The species considered in the selection of plots were spruce, balsam and jack pine. In classifying the plots for severity of burn only three degrees were established as follows:

Light burn: Bark at the base of trees lightly charred or occasionally lightly charred up one side of the tree for a short distance (Fig. 6). Trees so lightly charred that they remained alive were not included.

Moderately severe burn: Bark charred throughout full length of the tree but smaller twigs at most only partially consumed. Outer bark not deeply burned (Fig. 5).

Severe burn: Bark charred deeply throughout the length of the tree and smaller twigs consumed by fire (Figs. 1, 8, 9).

Richmond and Lejeune (1945) recognized five degrees of burn including one type more extreme than the "severe" burn as here described and one less extreme than the lightest category used here. In other words the three types used in this study correspond approximately with the middle three types of their classification. 


\section{Areas Reserved for Sample Plots}

In August, 1942, some 1400 trees on the six plots* were tagged and detailed observations for each tree were made. These included species, dia. meter, condition of bark, defects such as breakage, insect activity, and external evidence of decay. General observations for the plot as a whole were also recorded. Since 1942 the trees have been reexamined in August of each year. In addition to these examinations each year a number of trees on all plots have been analyzed by cutting the trees into 4-foot sections and measuring the actual volume of deductions caused by decay. In this connection it should be noted that heartrot which may have been present in the living tree was discounted as a factor of deterioration. It is more than likely that heartwood decay proceeds more slowly after death because of the dry con. dition of the wood. In any case, since the development of heartrot can not be considered as being initiated with the death of the trees, and although measurements of heartrot were taken in the course of the stem analyses, they were omitted in the final calculation of rate of deterioration. Sapwood decay, on the other hand, is known to have begun with the death of the tree and is either directly, or indirectly through breakage and windfall, the chief source of loss in pulpwood stands. The percentage of bark shed was based on ocular estimate for each tree and for purposes of broad comparisons is considered sufficiently accurate.

Plot 1: On the North Shore of the St. Lawrence River, Anglo-Canadian Pulp \& Paper Mills limits, on the Sault au Cochon River (Figs. 1, 2, 8, 9).

Judging by the bark charring and burning of the smaller twigs, the fire was extremely intense. All trees were charred throughout their length. The humus layer was entirely destroyed leaving only a black dust and a few coarse burned twigs over the mineral soil. The roots of all trees were badly exposed. Classified as severe burn.

Uneven-aged stand of balsam and spruce. Balsam 70 per cent, $65-120$ years old, average D.B.H. 5.8 inches. Spruce 30 per cent, 170 years old, average D.B.H. 9.8 inches. Scattered white birch. Total number of trees 207. Area of plot 0.7 acres.

This plot is situated on a flat creek bottom at the base of a north slope and well protected from the wind. The soil is fairly deep and the location generally moist. The ground cover had been entirely destroyed by the fire but in the second year after the fire a dense growth of willow, raspberry, cherry, and mountain ash appeared. A great deal of fireweed, Epilobium angustifolium, had also appeared.

Plot 2: On the North Shore of the St. Lawrence River, Anglo-Canadian Pulp \& Paper Mills limits, on the Sault au Cochon River (Figs. 3, 4).

The trees on this plot were charred throughout their length and the smaller twigs consumed by the fre. Classified as severe burn. The site is rocky with a shallow mineral soil and there has resulted an extreme exposure of the roots of the trees.

* The co-operation and assistance contributed by Price Bros. \& Co., Anglo-Canadian Pulp \& Paper Mills Ltd., and Consolidated Paper Corp. were largely responsible for making this J. O. Wilson and Mr. W. A. E. Pepler are also gratefully acknowledged. 
Spruce stand with some balsam and jack pine. Spruce 74 per cent, 80-90 years old, average D.B.H. 7.0 inches. Balsam 14 per cent, average D.B.H. 6.5 inches. Jack pine 12 per cent, average D.B.H. 8.8 inches. Total number of trees 228. Area of plot 0.5 acres.

This plot is on a shallow sandy gully along a creek with a large rock outcropping at one end of the plot. One year after the fire the ground cover was still very incomplete, composed mainly. of scattered Cornus cana. densis with some Vaccinium spp. and Aralia nudicaulis. The second year after the fire there was still little change but jack pine reproduction was beginning to appear. By the end of the fourth year the ground cover had come in densely to Cornus canadensis, Clintonia borealis, Vaccinium spp., with mainly jack pine reproduction and a few scattered spruce seedlings.

Plot 3: North of Lake St. John, on the Alex River, a tributary of the Peribonka River, Price Bros. limits.

Moderate burn in a pure spruce stand, 125.140 years of age, 853 trees with an average D.B.H. of 6.2 inches on an area of 1.6 acres (Figs. 5, 12, $13,14,15)$.

On a fairly moist, rocky site with a slight south-west slope well protected from the wind. The first year following the fire the ground cover was very incomplete, mainly Vaccinium spp. and Kalmia angustifolia with some Comus canadensis, Clintonia borealis, and Linnaea borealis. In some parts of the plot there were patches of Sphagnum. At the end of the third year spruce reproduction had begun and some alders appeared at the lower end of the plot.

Plot 4: North of Lake St. John, on the Alex River, Price Bros. limits. A light burn in an almost pure black spruce stand with an average D.B.H. of 5.2 inches, although 125,140 years old. A few scattered small larches. This plot was situated on a slight north slope, well protected on the east and west by rocky ridges. Very moist, rocky site. One year after the fire the ground cover was quite heavy with little evidence of the fire to be found. Vaccinium spp., Ledum groenlandicum, Kalmia angustifolia, and Sphagnum formed the principal cover, with some Cornus canadensis, Alnus sp., Chiogenes hispidula, Linnaea borealis, Coptis trifolia, and Carex sp. present (Fig. 6).

Plot 5: On the Corne River, St. Maurice River drainage, Consolidated Paper Corp. limits. Moderate burn in mixed softwood stand of spruce and jack pine with a few scattered balsam and white birch. Spruce 78 per cent, 120 years of age, average D.B.H. 7.6 inches. Jack pine 22 per cent, 130 years of age, average D.B.H. 9.3 inches. Total number of trees 602 . Area of plot 2 acres.

This plot is located on a hillside with a north slope of about 20 degrees and somewhat exposed to the wind. One year after the fire the ground cover on the lower slope consisted of Vaccinium spp., Ledum groenlandicum, Kalmia angustifolia, Clintonia borealis, and Linnaea borealis, while on the upper slope there were in addition Cornus canadensis, Streptopus roseus, Maianthemum canadense, and Coptis trifolia. There has been little change in the ground vegetation during the first five years since the fire (Figs. 7, $10,11)$. 


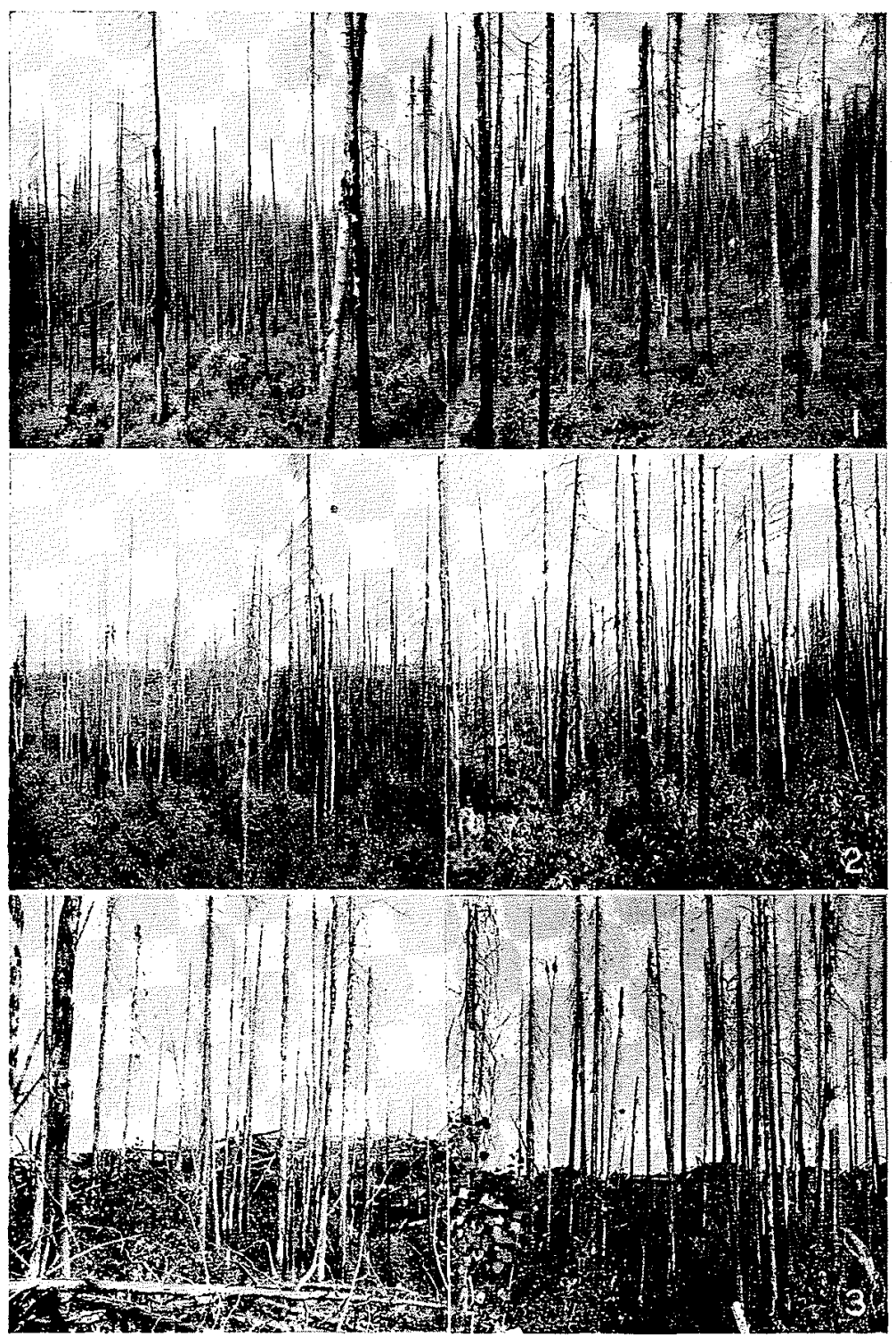

Fig. 1-General view of plot 1, spruce and balsam, two years after severe inre. Fig. 2-General view of plot 1 , five years after severe fire. 


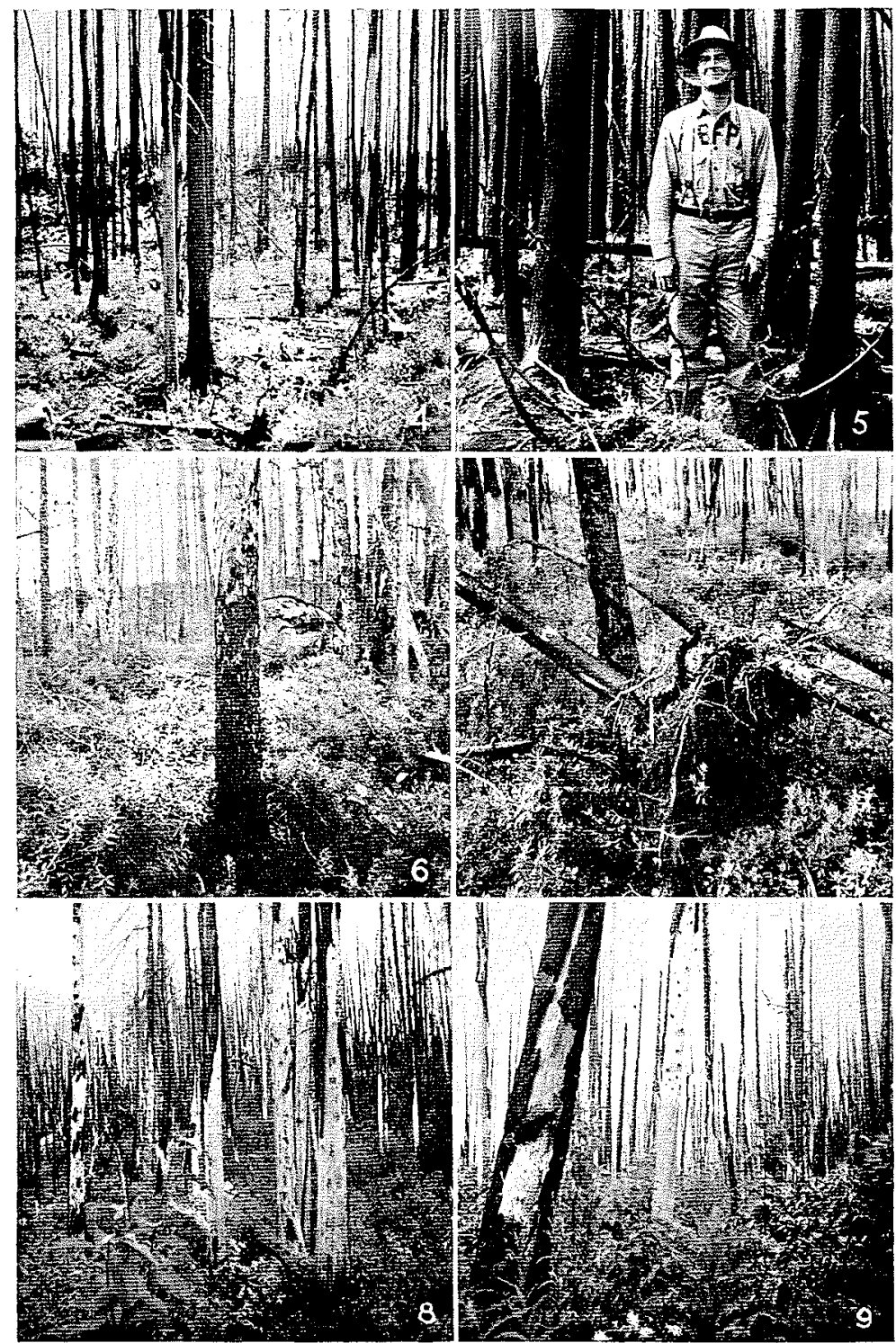

Fig. 4-Two years after severe fire on plot 2 no bark has been shed by mruce. The slowness of bark shedding on this plot is believed to be a result of the dry conditions of the site and small diameter of the trees.

Fig. 5- Spruce stand one year after moderately severe fire. Although charred throughout no bark is shed in the first year. Note severe ground burning and exposure. Plot 3 .

Fig. 6- Spruce lightly charred in lower part only. Two years after fire no bark has been shed. Ground cover complete. Plot 4.

Fig. 7-Uprooting of spruce on plot 5, five years after moderate fire. This is the chief source of loss during the first five years after severe or moderately severe fire.

Fig. 8-Bark shedding in balsam after severe fire. Two years after fire the bark in the lower part of the trunk and hangs in loose "scrolls" in the upper part Plot 1.

Fig. 9-Comparison of bark shedding in spruce (left foreground) and balsam (centre and left background) two years after severe fire. Plot 1 . 
Plot 6: North of Lake St. John, on the Alex River, Price Bros. limits. Light to moderate burn. The trees on this plot were grouped as moderate burn when charred throughout or light if burned at the base or up one side.

The stand in which this plot was located consisted of about 70 per cent balsam and 30 per cent spruce, with scattered large white birches. However, only the balsam trees were marked for observation and these were scattered over several low ridges but well protected by surrounding hills. Some 242 trees having an average D.B.H. of 7.0 inches and about 100 years of age were marked. Size of plot indefinite. A dense young stand of balsam. reproduction was coming in at the time of the fire.

The plot was located on low, rocky ridges running east and west. One year after fire the ground cover was very incomplete, consisting of Cornus canadensis, Aralia nudicaulis, and Maianthemum canadense. There was little change in the ground vegetation in the first three years.

\section{Results of the Study to Date}

It is generally assumed that for a given species the severity of burn determines the rate of bark shedding which in turn affects the rate of deterioration. The rate of bark shedding and deterioration may be expected to vary consider. ably with the tree species. To what extent the results of this study to date support such an assumption may best be illustrated by considering the evidence of correlations separately.

\section{Bark Shedding}

1. Correlation between severity of fire and bark shedding:

From Table I it will be noted that for spruce, with the exception of the severely burned plot 2 , the severity of fire markedly influences the rate and amount of bark shed. (See Figs. 1, 2, 3, 4). For example, on plot 1, although no bark was shed in the first year, during the second year it was estimated that 43 per cent had been shed and that by the end of the fifth year 73 per cent had fallen from the trees. This compares with 7 per cent and 9 per cent at the end of the second year for the moderately burned plots 5 and 3 respectively and 45 per cent and 48 per cent at the end of the fifth year (Fig. 10). The lightly burned plot 4 showed no loss of bark up to the end of the second year (Fig. 6), at which time unfortunately the unrestricted enthusiasm of some jobber for closer utilization removed the plot from further experimental consideration. Essentially similar comparisons may be noted for jack pine and balsam.

2. Correlation between diameter of trees and bark shedding:

To account for the low percentage of bark shed on plot 2 as compared with plot 1 there are several possible explanations. It has been found that the percentage of bark shed may be correlated with the diameter of the trees. This may be illustratd by Table II, which shows percentage of bark shed by diameter classes for plot 3 (spruce). 


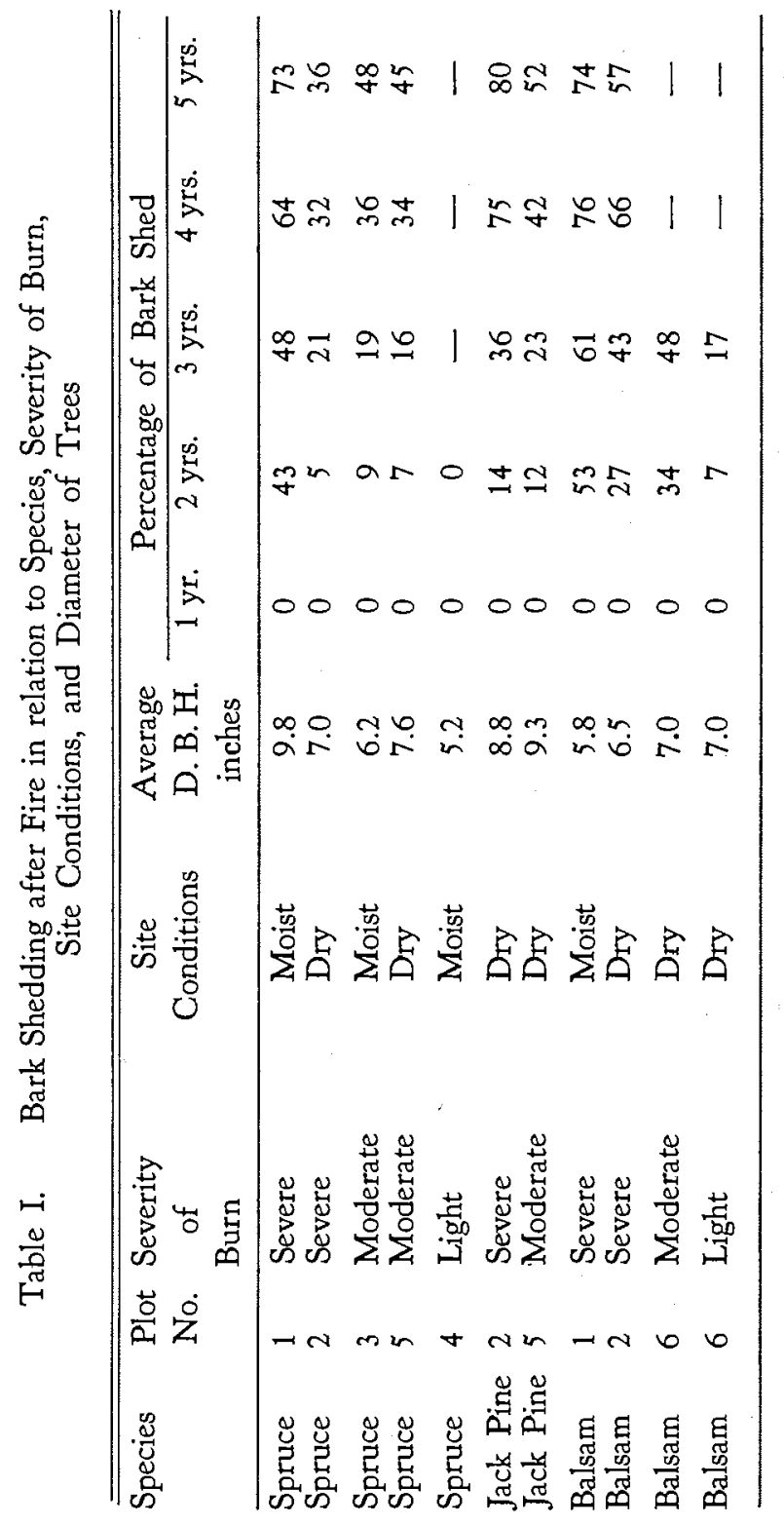


FIRE-KILLED PULPWOOD—SKOLKO

Table II. Percentage of Bark Shed according to Diameter Classes.

\begin{tabular}{cccccc} 
& \multicolumn{5}{c}{ Spruce, Plot 3, Moderate Burn } \\
D. B. H. & 1 yr. & 2 years & 3 years & 4 years & 5 years \\
3 & 0.0 & 1.5 & 3.1 & 8.7 & 15.6 \\
4 & 0.0 & 2.2 & 4.5 & 10.3 & 16.0 \\
5 & 0.0 & 3.5 & 7.7 & 19.1 & 29.0 \\
6 & 0.0 & 9.8 & 15.7 & 32.9 & 48.8 \\
7 & 0.0 & 17.4 & 29.3 & 54.3 & 68.1 \\
8 & 0.0 & 20.8 & 32.5 & 54.8 & 70.7 \\
9 & 0.0 & 23.3 & 38.7 & 63.4 & 77.2 \\
10 & 0.0 & 29.8 & 39.9 & 65.5 & 73.3 \\
11 & 0.0 & 27.5 & 50.0 & 55.0 & 72.5 \\
12 & 0.0 & 23.3 & 47.5 & 65.0 & 95.0 \\
14 & 0.0 & 50.0 & 70.0 & 85.0 & 95.0
\end{tabular}

This correlation between diameter and percentage of bark shed holds true for all the plots. This might account for the difference between the severely burned plots 1 and 2 since plot 1 had an average D.B.H. of 9.8 inches for spruce while plot 2 had only an average D.B.H. of 7.0 inches. On the other hand the less severely burned plots 3 and 5 had an average D.B.H. of 6.2 and 7.6 inches respectively, yet showed about the same percentage of bark shedding as plot 2 .

3. Correlation between site conditions and bark shedding:

It has been suggested that cambial activity of the trees during the spring (the so'called "sap run") which is possibly related to the moisture conditions of the site affects the adhesion of the cambium and bark of trees killed by fire. If there is any truth in this suggestion then the dry sandy site conditions on plot 2 might be held responsible for the apparent discrepancy between severity of fire and bark shedding. Essentially similar results showing the correlation between site conditions and bark shedding may be noted for balsam on plots 1 and 2. For moderately burned spruce on plots 3 and 5 the effect of site conditions seems less marked.

The general effect of exposure has also been noted. It has been observed that the bark is usually shed first on the west side of the trees. The explanation of this phenomenon may be the prevailing westerly winds or alternate thawing and freezing with the expansive action of the ice between the bark and wood during the late afternoon in early spring, or a combination of the two. It may even be related to the direction in which the fire passed, charring the trees more severely on one side.

4. Correlation between species and bark shedding:

In comparing the proportion of bark shed between species, although the data for such a comparison are limited, it will be noted that on plot 1 balsam sheds its bark faster than spruce in spite of the smaller average diameter of the trees (Figs. 8,9). On Plots 2 and 5 jack pine sheds its bark faster than spruce although here the complication of larger diameters of the jack pine must be considered. The comparison between balsam and jack pine on plot 2 must be made with reservation because of the disparity in size of the trees 
and the small number of trees involved. If this can be disregarded then it would appear that balsam has shed its bark faster in the first three years but that by the end of the fourth year jack pine has actually shed a higher proportion of bark. One possible explanation for this may be in the manner in which the bark is shed in balsam. The continuous nature of the periderm results in large "scrolls" of bark falling away at one time (Fig. 8). In jack pine the deeply fissured bark permits of smaller pieces being detached. In this respect jack pine is like spruce. The feeding activity of woodpeckers seeking wood-boring insects in the killed trees is often a significant factor in bark removal.

Aside from any possible correlation between amount of bark shed and subsequent decay, there is a very direct effect of bark shedding upon the weathering of the exposed wood. This weathering results in a discolouration of the outer wood and constitutes a further obstacle in the utilization of fire-killed pulpwood. It has also been observed that on severely burned plots the rapidity of bark shedding in balsam seems to discourage the activity of wood-boring insects. Rarely have such trees been found attacked.

\section{Deterioration}

In calculating the rate of deterioration three distinct sources of deduction have been considered, (1) saprot, (2) breakage, and (3) windfall or uprooting. That these three sources of deterioration are not independent is obvious. In actual salvage operations the incidence of breakage and windfall usually determines the limit of salvage practicability. Depending upon exposure, a small percentage of saprot, insufficient in itself to make salvage economically impractical, may weaken the trees to the point where excessive breakage occurs. Once the trees have fallen decay proceeds so rapidly that it is unlikely that salvage is worthwhile, although this has sometimes been attempted. Breakage owing to heartrot have been included for the reason that this type of damage is hastened by the exposure of the trees to wind as a direct result of the fire. The connection between uprooting and decay is not so clear but doubtless does exist. The more obvious relation to exposure, weakening of the root system, and the retentive ability of the soil have suggested that deductions for windfall be kept separately from breakages in order that correlations might be clearer. In Table III a summary of all deductions which are considered to be attributable to the fire is presented by species in relation to severity of burn.

Before attempting any interpretation of Table III it should be emphasized that the data on sapwood decay were based of necessity upon a small number of stem analyses so that absolute values must not be taken too literally. They do, however, give some indication of the relative magnitude of saprot deductions and allow for comparison. The irregularity in percentages may reasonably be attributed to this cause. It is questionable whether larger samples would be justified or would give closer comparisons in view of the broad classification of severity of burn, site conditions and of the possible application of the data. The figures for the other defects were based upon detailed examination of all the trees on the plots. 


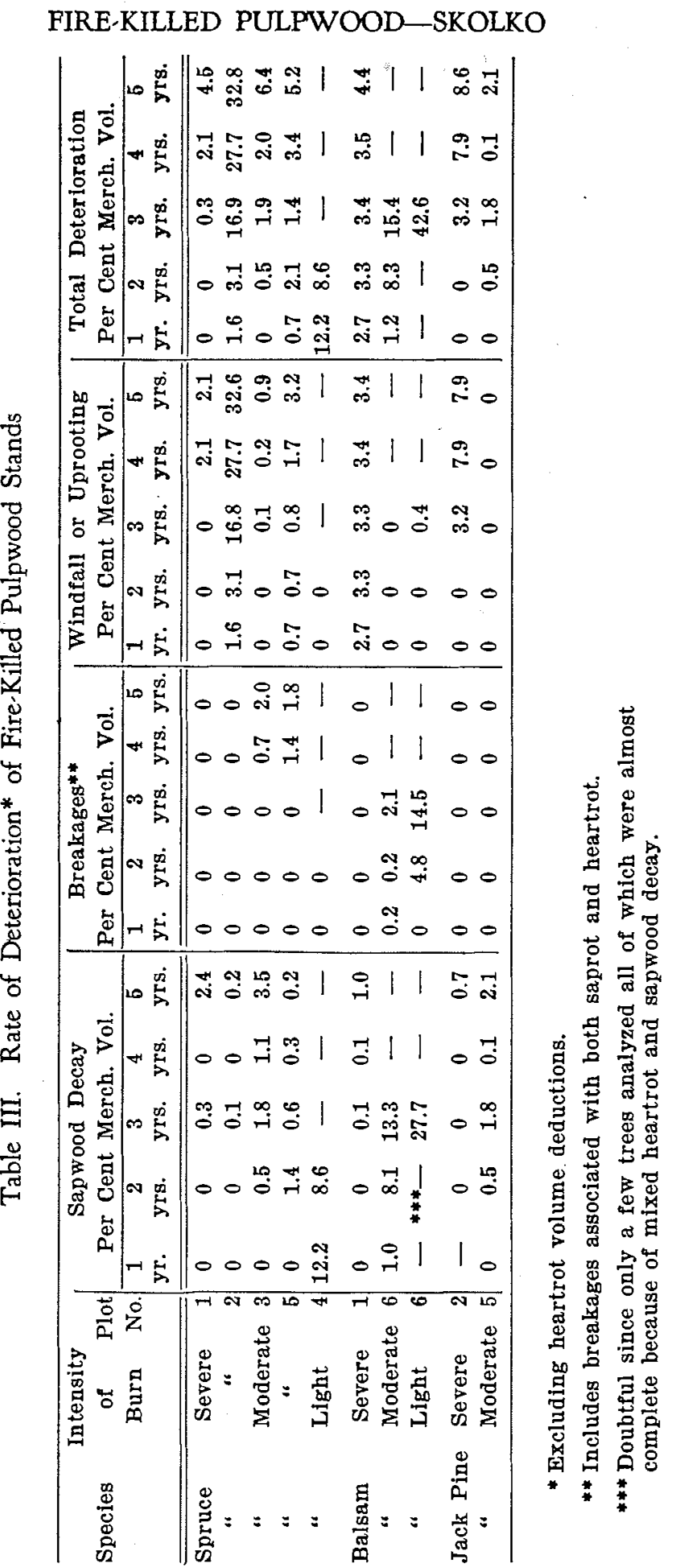


Considering the spruce plots first it will be noted that even at the end of the fifth year the percentage of sapwood decay is extremely low, except on the lightly burned plot 4 . On plot 4 even at the end of the first year sapwood defects were relatively high. Plots 1 and 3 with 2.4 per cent and 3.5 per cent sapwood decay respectively at the end of five years indicate the influence of site conditions since these plots were classified as moist sites as compared with 0.2 per cent for plots 2 and 5 which were considered to be dry sites. Breakages owing to both sapwood decay and heartrot were also very low. Windfall or uprooting became serious on plot 2 because of the exposure at one end of the plot. There, a rocky outcrop and shallow sandy soil gave little support to the trees. Plot 5 also had a higher percentage of loss through windfall than plot 3 because of the sandy soil and greater exposure. Disregarding the factor of windfall (and heartrot), it will be seen that the rate of deterioration for spruce after severe or moderately severe burn during the first five years after fire is extremely low, actually only 5.5 per cent for the moderately burned, moist site of plot 5 . On the basis of these data it would appear that exposure to wind and perhaps depth of soil exert the greatest influence on rate of deterioration in the first five-year period after fire.

In spruce it was found that on severe and moderately severe burns, the extremely dry condition of the wood is evidently highly unfavourable for fungus development. There has been even to this time little evidence of blue-staining fungi. After the second year some pitted saprot caused by Polyporus abietinus (Dicks.) Fr. appeared but since only a very small part of the outer sapwood is affected, loss from this cause was not significant (Fig. 15). As the wood dried considerable checking occurred. It is believed that this checking provided more favourable moisture conditions for the development of decay caused by Lenzites saepiaria (Wulf.) Fr. The brown cubical rot caused by this fungus was found to follow the checks extending for some distance vertically on the trunk and in transverse section following the radial cracks without much tangential expansion. Most decay of this type was found in the lower three feet of the trunk with abundant production of sporophores or conks in this region or on the exposed roots near the root crown (Figs. 11, 12, 13, 14). It was found to be the principal source of sapwood deductions and its concentration in the lower part of the trunk is expected to be the chief cause of future breakage, as has already been indicated. This decay is very common in timber in service, which indicates the low moisture requirements of the fungus. Sapwood decay caused by Fomes pinicola (Swartz) Cke. which has been found to be one of the most serious decays in insect-killed spruce was notably lacking, probably because of the dry condition of the wood.

Considering next the rate of deterioration as found on the balsam plots, it will be noted from Table III that on the severely burned plot 1 there was little difference between balsam and spruce. The chief difference lay in the amount of windfall which was somewhat higher for balsam. The total percentage of deterioration was estimated at the end of the fifth year as only 
4.4 per cent. This may be surprising in view of the general belief that balsam deteriorates much more rapidly than spruce. If a comparison is made between the moderately burned balsam on plot 6 and spruce on plots 3 and 5 , it will be seen that balsam apparently does deteriorate faster under conditions of moderate burn. The lightly burned balsam on plot 6 shows a rela. tively high rate of deterioration, amounting to over 42 per cent at the end of the third year. Unfortunately fourth year observations on plot 6 were precluded by unauthorized cutting of the trees. In considering salvage plans for such a stand an estimate for heartrot which is usually high in balsam must be included.

For jack pine on severe and moderate burns the rate of deterioration was surprisingly low, the greatest loss on the severely burned plot 2 being a result of windfall. The moderately burned plot 5 showed a slightly higher percentage of sapwood decay than the severely burned plot 2, as would be expected. Jack pine, although relatively free from advanced sapwood decay, became badly stained even in the first year. The discoloration is usually a mixture of red and blue stain which involves all the sapwood in radial streaks. After the first year there appears to be little increase and no deduction was made for this defect.

One factor which it has not been possible to consider in this study is the time of year of fire. It is known that the season of fire determines the course of subsequent insect infestation. It has been suggested that season of fire may exert a considerable influence on the rate of bark shedding and on rate of decay. No data substantiating or disproving this point have been collected in the present investigation. It does seem logical, however, to believe that trees killed by fall fires and subjected to winter drying, a period when fungous activity has ceased or is greatly retarded, would be in a better position to withstand fungous attack than those killed by spring fires. The results of the present study would indicate that even after spring fires the rate of decay for severely burned trees at least is so low that time of year of fire may not be as important as is generally held.

\section{SUMMARY}

To summarize the results to the end of the fifth year the following con. clusion may be drawn:

1. The rate of bark shedding is directly proportional to the severity of the fire and to the diameter of the trees. In cases of severe fire it may be influenced by some other factor or factors, possibly moisture conditions of the site.

2. The rate of bark shedding is greatest in balsam and slightly higher in jack pine than in spruce, especially during the first three years after fire.

3. The rate of deterioration is correlated with severity of fire.

4. The rate of deterioration after severe fire is of the same order for spruce, balsam and jack pine for the first four years, amounting to less than 1 per cent if windfall and heartrot are discounted. Even under moist conditions it is less than 3 per cent for spruce after five years.

5. Under conditions of moderate burn balsam deteriorates more rapidly than spruce or jack pine. 
6. Jack pine, even after severe fire, becomes heavily stained in the first year.

7. In view of the much higher rate of deterioration of moderately burned balsam over spruce and pack pine, in spite of the fact that balsam has shed its bark more rapidly, it appears that bark shedding and rate of deterioration are only proportional within specific limits. That the rate of bark shedding and rate of deterioration are not always closely correlated is further seen in the low percentage of decay on one of the severely burned plots which had a low percentage of bark shed.

The practical recommendations which may be drawn from the study to date are clearly indicated, namely, that after severe or moderately severe fire the greatest losses can be expected in areas where exposure to wind and shallow soil may result in excessive windfall. These areas should be cut first. The low percentage of decay on moderately severe and severely burned areas indicates that losses from this cause are only of secondary importance at least for the first five years. In view of the fact that most decay is localized in the lower three feet of the trunk it might be expected that a relatively low percentage of decay may result in considerable breakage in this region. Examinations in the next few years should make this point clear.

\section{REFERENCES}

Beal, J. A., J. W. Kimmey, and E. F. Rapraeger, 1935. Deterioration of fire-killed Douglas fir.

Timberman $37(2): 12-17$.

Furniss, R. L., 1937. Salvage on Tillamook burn as affected by insect activity. Timberman 39(2): 11.13, 30-32.

Kimmey, J. W., and R. L. Furniss,

1943. Deterioration of fire-killed Douglas fir.

Knapp, J. B. U.S. Dept. Agr. Tech. Bull. 851: 1.61.

1912. Fire-killed Douglas fir: a study of its rate of deterioration, usability, and strength. U.S. Dept. Agr. For. Serv. Bull. 112: 1.18 .

Pepler, W. A. E.

1931. The rate of deterioration of pulpwood in the woods. Wood. lands Section, Can. Pulp and Paper Assoc. 5 pp. Jan. 1931.

Richmond, H. A. and R. R. LeJeune,

1945. The deterioration of fire-killed white spruce by wood. boring insects in northern Saskatchewan. Forestry Chron.

Riley, C. G. $21(3): 168-192$

1940. Deterioration in insect-killed spruce on the Gaspe Peninsula. Pulp and Paper Magazine of Canada 41: 611-612. Aug., 1940.

Riley, C. G., and A. J. Skolko,

1942. Rate of deterioration in spruce killed by the spruce sawfly. Pulp and Paper Magazine of Canada 43(7):521-524. June, 1942. 


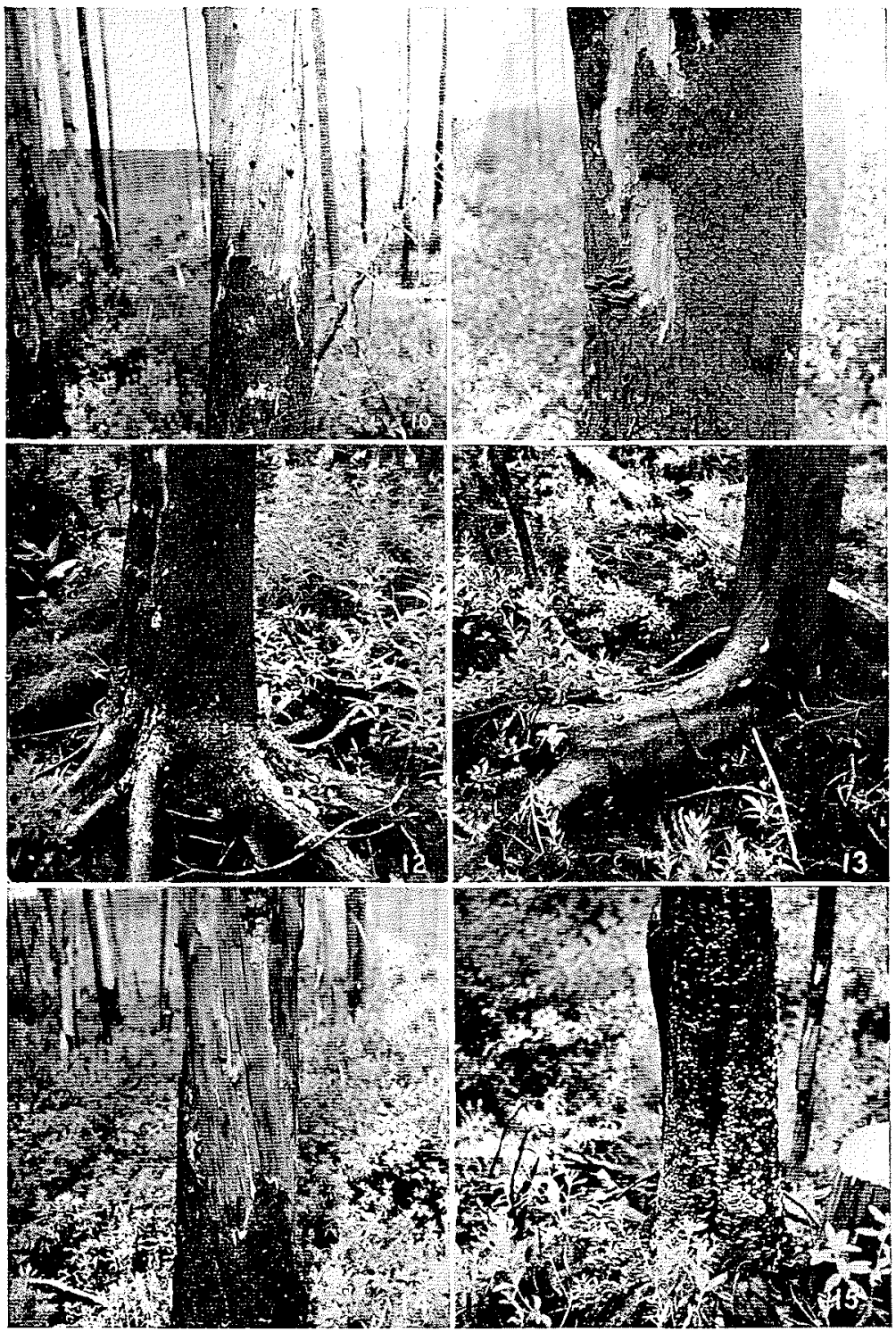

Fig. 10-Five years after moderately severe fire spruce has shed a large part of its bark. Except in the lower foot or two, the wood has checked and become discoloured by exposure. Plot 5 .

Fig. 11-Lenzites saepiaria sporophores on spruce five years after moderate fire. Note the small vertically arranged sporophores above the main cluster following the checking of the wood. Plot 5 .

Fig. 12 and 13-Lenzites saepiaria sporophores on the base and exposed roots of spruce two years after moderately severe fire. Plot 3.

Fig. 14-Sporophores and advanced decay caused by Lenzites saepiaria on spruce five years after moderate fire. Plot 3.

Fig. 15-Sporophores of Polyporus abietinus on spruce five years after moderately severe fire. Plot 3. 